\title{
Development and evaluation of a PCR-based immunoassay for the rapid detection of methicillin-resistant Staphylococcus aureus
}

\author{
K. J. TOWNER, D. C. S. TALBOT*, R. CURRAN, C. A. WEBSTER and H. HUMPHREYS
}

Department of Microbiology and PHLS Laboratory, University Hospital, Queen's Medical Centre, Nottingham NG7 2 UH and*Biorecognition, Unilever Research, Colworth Laboratory, Sharnbrook, Bedfordshire MK44 $1 L Q$

\begin{abstract}
A multiplex polymerase chain reaction (PCR), involving detection of the $m e c A$ and fem $B$ genes, was combined with a novel immunoassay system capable of detecting specific PCR products. The resulting PCR-immunoassay was evaluated in comparison with conventional microbiological techniques used in the routine diagnostic laboratory for the rapid identification of methicillin-resistant Staphylococcus aureus (MRSA), either in pure culture or in overnight broth cultures obtained following enrichment of patient screening swabs. Among the 480 purified isolates of staphylococci and 246 enrichment broths examined, only one 'false-negative' result was obtained by PCR, compared with 18 'false-negative' results obtained by conventional methodology and demonstrated by further conventional examination. Five demonstrable 'false-positive' results were obtained by conventional methodology, compared with a possible 10 by the PCRimmunoassay, although it was not certain that these 10 PCR results were true 'false positives' as, by definition, MRSA could not be isolated by conventional methodology. The results indicated that the routine diagnostic laboratory was encountering difficulties in identifying MRSA correctly, and that the conventional microbiological techniques lacked sensitivity. Overall, the PCR technique was more accurate and sensitive than conventional methodology in detecting MRSA, and results were available within $24 \mathrm{~h}$ of screening swabs arriving in the laboratory, compared with a minimum of $48-72 \mathrm{~h}$ by conventional techniques. The immunoassay system added to the usefulness of the method by allowing the detection of specific PCR products within $5 \mathrm{~min}$ of completing the PCR, without the normal additional step of agarose gel electrophoresis.
\end{abstract}

\section{Introduction}

Staphylococcus aureus is found in the nose and on the skin of a variable number of healthy individuals, and is an opportunist pathogen in patients with lowered host resistance. The isoxazolylpenicillins (e.g., methicillin, cloxacillin, flucloxacillin, etc.) have been the mainstay of treatment for well over 25 years, but the emergence of strains (referred to as methicillin-resistant $S$. aureus; MRSA) resistant to this group of compounds and all other $\beta$-lactam agents poses increasing problems, especially in hospitals, because of the propensity of certain epidemic MRSA strains to spread and colonise

Received 4 Sept. 1997; revised version accepted 8 Nov. 1997.

Corresponding author: Dr K. J. Towner.

E-mail: Kevin.Towner@nott.ac.uk debilitated patients. Such strains may or may not be resistant to multiple antibiotics, leading to potential difficulties in treating systemic infections $[1,2]$.

In the UK, epidemic strains have been numbered sequentially on the basis of phage typing (i.e., EMRSA-1, EMRSA-2, etc.), and three well-defined strains (EMRSA-3, EMRSA-15 and EMRSA-16) continue to affect hospitals in England and Wales, with the incidence of EMRSA-15 and EMRSA-16 increasing in particular [3]. The identification of MRSA in a hospital ward may warrant immediate patient isolation (and occasional ward closure), screening of patient contacts and staff, and appropriate disinfection measures. Screening for carriers, rather than simply identifying infected patients, has a major role in control of an outbreak and reduces the number of infections [3]. However, the results of screening may not be available for at least $48 \mathrm{~h}$, resulting in 
considerable disruption, reduced patient throughput, frustration for patients, their families and clinical colleagues, and substantial extra costs to host units. Although assessment of the true costs of controlling MRSA colonisation (leading to infection) is difficult, the cost of containing a recent outbreak in Kettering, UK (involving over 400 patients) was estimated to be in excess of $£ 400000$ (c. US $\$ 650000$ ), of which the provision of isolation wards accounted for a large proportion [4]. Other direct and indirect costs included those associated with patient and staff screening, extra staff, disinfectants, protective clothing, cleaning, prolonged hospital stays, ward closures (with consequent reduced clinical activity), redeployment of staff, and additional costs such as secretarial time, telephone calls, etc.

Accurate determination of methicillin resistance in staphylococci by conventional MIC tests is subject to variations in inoculum size, incubation time, medium $\mathrm{pH}$, medium salt concentration, etc. As a consequence, PCR-based methods are being used increasingly by reference laboratories as the 'gold standard' for detecting methicillin resistance [5], particularly because false-positive or false-negative reports of resistance may have considerable economic importance when hospital wards are being opened or closed, with or without the institution of costly control of infection measures, on the basis of whether or not an outbreak of MRSA infection is occurring. However, detection of specific PCR products normally requires an electrophoresis step on agarose or polyacrylamide gels, and this requirement limits the number of assays that can be completed within a working day and complicates the introduction of PCR tests into routine diagnostic laboratories. A previous study described the application of a novel user-friendly immunoassay system to the rapid detection of PCR products derived from TEM $\beta$-lactamase genes [6]. The present study describes the further development of this method for the rapid and specific detection of MRSA, and includes an evaluation of the method, in comparison with conventional bacteriological techniques, for the detection of MRSA in screening samples obtained routinely from patients for hospital infection control purposes.

\section{Materials and methods}

\section{Bacteria}

Initial evaluation of the specificity of the PCRimmunoassay method (see below) was performed with DNA extracted from 480 isolates of staphylococci identified previously by in-house methods based on standard microbiological criteria [7], including DNAase and coagulase tests, as either $S$. aureus (152 isolates) or $S$. epidermidis (328 isolates). Of the $152 \mathrm{~S}$. aureus isolates, 40 were identified originally by the routine diagnostic laboratory as MRSA or '?MRSA'.

\section{Examination of routine patient screening} specimens for $M R S A$

Swabs obtained from various patient body sites (e.g., nose, axilla, perineum, etc.) for routine hospital infection control purposes were pooled into $10-\mathrm{ml}$ portions of enrichment broth, consisting of Nutrient Broth (Oxoid) containing $\mathrm{NaCl} 7 \% \mathrm{w} / \mathrm{v}$ and methicillin (Sigma) $4 \mathrm{mg} / \mathrm{L}$, and incubated overnight at $30^{\circ} \mathrm{C}$. For detection of MRSA by the PCR-immunoassay method, $100-\mu 1$ portions of the broth were removed following the enrichment step and the DNA was released by one of the three methods described below. For detection of MRSA by conventional bacteriological techniques, a 5$\mu l$ portion of the enrichment broth was plated on Mannitol-Salt Agar (Oxoid), incubated overnight at $37^{\circ} \mathrm{C}$ and then examined for 'typical' yellow staphylococcal colonies, followed by further confirmatory identification and susceptibility tests as deemed necessary. In total, 146 random sets of screening swabs (each set comprised pooled swabs from up to six body sites on an individual patient) were examined by both methods. In addition, 100 swabs obtained from defined body sites on 13 patients shown previously by conventional methods to be colonised by MRSA were processed individually in enrichment broth and then examined by both methods. When required, viable counts were performed by plating out appropriate dilutions in sterile saline $(\mathrm{NaCl} 0.7 \% \mathrm{w} / \mathrm{v})$ on to CLED Agar (Oxoid).

\section{The PCR-immunoassay method for detecting $M R S A$}

The PCR-immunoassay detection method was based on the use of a multiplex PCR that detected simultaneously the mecA and $f e m B$ genes. The mecA gene encodes the $S$. aureus penicillin-binding protein (PBP2a, also known as PBP2') that is the structural determinant for methicillin resistance [8]; $\mathrm{fem} B$ is involved in pentaglycine side-chain formation and interpeptide bridge formation, as well as expression of methicillin resistance $[8,9]$. It has been reported that $f e m B$ is not found in coagulase-negative staphylococci [10] but is highly conserved in $S$. aureus $[10,11]$. Oligonucleotide primers used to generate dual-labelled mecA and $f e m B$ PCR products are listed in Table 1.

DNA extraction. Three different techniques were evaluated for their efficiency in releasing staphylococcal DNA from cells in enrichment broth cultures: (1) heating broth cultures to $95^{\circ} \mathrm{C}$ for $15 \mathrm{~min}$; (2) a standard procedure in which lysostaphin was used to lyse the cell walls [12]; and (3) a rapid procedure in which $1-\mu 1$ portions of enrichment broth containing bacteria were exposed to a short period $(7 \mathrm{~min})$ of microwave radiation in the presence of $20 \mu \mathrm{l}$ of Recovery $^{\mathrm{TM}}$ reagent (Hybaid, Teddington, Middlesex) following the protocol recommended by the manufacturer. Efficiency of DNA release was monitored by a 
Table 1. Oligonucleotide primers used to generate specific dual-labelled PCR products

\begin{tabular}{|c|c|c|c|c|c|}
\hline Primer & Label & Sequence & Target & Product $(\mathrm{bp})$ & Reference no. \\
\hline MecA1 & Triple-DNP & 5'-GTAGAAATGACTGAACGTCCGATAA & $m e c A$ gene & 310 & 12 \\
\hline $\mathrm{MecA} 2$ & Biotin & 5'-CCAATTCCACATTGTTTCGGTCTAA & & & \\
\hline FemB1 & Triple-DNP & 5'-TTACAGAGTTAACTGTTACC & fem $B$ gene & 651 & 10 \\
\hline FemB2 & DIG & 5'-ATACAAATCCAGCACGCTCT & & & \\
\hline $\mathrm{X}$ & Triple-DNP & $5^{\prime}$-GGAATTCAAA ${ }^{\mathrm{T}} /{ }_{G}$ GAATTGACGGGGGC $^{-}$ & $16 \mathrm{~S}$ rDNA & 479 & 6 \\
\hline Y & DIG & 5'-CGGGATCCCAGGCCCGGGAACGTATTCAC & & & \\
\hline
\end{tabular}

DIG, digoxigenin; DNP, dinitrophenol.

separate PCR [6] designed to amplify a conserved region of DNA encoding bacterial 16S rRNA (Table 1).

PCR conditions for detection of MRSA. For the multiplex PCR, each $25-\mu 1$ reaction mix contained 2.5 pmol of each of the four labelled primers for mecA and $\mathrm{femB}$ (Table 1), $0.2 \mathrm{mM}$ dNTPs, $1.5 \mathrm{mM} \mathrm{MgCl}_{2}$, $0.6 \mathrm{U}$ of $\mathrm{Taq}$ polymerase (Boehringer) and $4 \mu \mathrm{l}$ of bacterial DNA extract (prepared as above). Amplification conditions (GeneE Thermocycler; Techne, Cambridge) comprised $4 \mathrm{~min}$ at $94^{\circ} \mathrm{C}$, followed by 30 cycles of $45 \mathrm{~s}$ at $94^{\circ} \mathrm{C}, 45 \mathrm{~s}$ at $50^{\circ} \mathrm{C}$ and $1 \mathrm{~min}$ at $72^{\circ} \mathrm{C}$, followed by $2 \mathrm{~min}$ at $72^{\circ} \mathrm{C}$.

Detection of PCR products. After completion of the PCR, $1 \mu \mathrm{l}$ of each reaction mix was added to $99 \mu \mathrm{l}$ of TBE buffer $(89 \mathrm{mM}$ Tris, $89 \mathrm{~mm}$ boric acid, $2 \mathrm{mM}$ EDTA, $p H$ 8.0) and then applied $(100 \mu 1)$ to a Clearview $^{\mathrm{TM}}$ (Unipath) immunoassay detection device. These devices have been described previously [6] and, in brief, consist of a small plastic fitting enclosing: (1) a sample application pad containing blue latex beads coated with an anti-dinitrophenol (DNP) antibody; and (2) a membrane coated with discrete lines of anti-biotin antibody and anti-digoxigenin (DIG) antibody. The labelled primers listed in Table 1 were designed to generate dual-labelled PCR products - i.e., a mecA product labelled with DNP and biotin, and a $\operatorname{fem} B$ product labelled with DNP and DIG. In the presence of a specific dual-labelled end-product, the blue latex beads (coated with anti-DNP) localise to either the antibiotin or anti-DIG lines on the membrane, yielding an easy-to-read blue line as an end-point. Results are usually obtained within 5 min without washes or any additional manipulations [6]. Any dual-labelled PCR products would be detected by the system [6], including non-specific amplification products. Therefore, for the evaluation purposes of this study, the remaining $24-\mu 1$ portion of each $25-\mu 1$ PCR reaction mix was also analysed by electrophoresis on agarose (Electrophoresis Grade; Gibco BRL) $2 \%$ w/v gels, staining with ethidium bromide and visualisation of PCR products on a UV transilluminator by standard techniques [13].

\section{Results}

\section{Efficiency of DNA extraction}

Staphylococci are known to be difficult to lyse, but a prerequisite for a rapid PCR-based method of detecting
MRSA was an efficient, simple and quick method for DNA release from staphylococcal cells. The three procedures described in Materials and methods (heating to $95^{\circ} \mathrm{C}$ for $15 \mathrm{~min}$, the lysostaphin method and the Hybaid method) were evaluated with 10 -fold dilutions of an overnight broth culture of a known strain of MRSA. Ten duplicate extractions at each dilution were performed with each method, followed by a PCR targeting the conserved region of DNA encoding bacterial 16S rRNA. The results obtained are summarised in Table 2. The Hybaid DNA extraction method was significantly more efficient, yielding positive PCR results in all 10 independent DNA extractions with as few as $40 \mathrm{cfu}$ in the $1-\mu 1$ portion of broth examined (equivalent to $4 \times 10^{4} \mathrm{cfu} / \mathrm{ml}$ in the original enrichment broth). In comparison, heating to $95^{\circ} \mathrm{C}$ for $15 \mathrm{~min}$ and the lysostaphin method required a minimum of $4 \times 10^{8}$ or $4 \times 10^{7} \mathrm{cfu} / \mathrm{ml}$, respectively, to give a positive PCR result with all 10 independent DNA extractions at a particular dilution. Following these observations, all further PCR experiments were performed with the Hybaid method.

\section{Use of femB to recognise $S$. aureus}

The $f e m B$ gene is known to be involved in controlling the level of methicillin resistance in $S$. aureus, but has been reported not to occur in coagulase-negative staphylococci [10]. As a first step in developing a direct test for MRSA in screening samples, the occurrence of the $f e m B$ gene in purified clinical isolates was examined in duplicate PCRs and the

Table 2. Comparison of the efficiency of three methods used for release of DNA from an enrichment broth culture of a known strain of MRSA

\begin{tabular}{|c|c|c|c|}
\hline \multirow{2}{*}{$\begin{array}{l}\text { Viable } \\
\text { count } \\
(\mathrm{cfu} / \mathrm{ml})\end{array}$} & \multicolumn{3}{|c|}{$\begin{array}{c}\text { Percentage of identical samples yielding a positive } \\
\text { PCR result* }\end{array}$} \\
\hline & $\begin{array}{l}\text { Heating } \\
\text { method }\end{array}$ & $\begin{array}{l}\text { Lysostaphin } \\
\text { method }\end{array}$ & $\begin{array}{l}\text { Hybaid } \\
\text { method }\end{array}$ \\
\hline $4 \times 10^{8}$ & 100 & 100 & 100 \\
\hline $4 \times 10^{7}$ & 80 & 100 & 100 \\
\hline $4 \times 10^{6}$ & 40 & 50 & 100 \\
\hline $4 \times 10^{5}$ & 0 & 10 & 100 \\
\hline $4 \times 10^{4}$ & 0 & 0 & 100 \\
\hline $4 \times 10^{3}$ & 0 & 0 & 70 \\
\hline $4 \times 10^{2}$ & 0 & 0 & 30 \\
\hline $4 \times 10^{1}$ & 0 & 0 & 0 \\
\hline
\end{tabular}

* Ten identical DNA extractions were performed by each method at each dilution, followed by a PCR [6] designed to amplify a conserved region of DNA encoding bacterial $16 \mathrm{~S}$ rRNA. 
results were compared with those obtained from DNAase and coagulase tests. Of the 480 isolates examined, 151 were positive in both of the duplicate PCRs for the $f e m B$ gene, and were also DNAasepositive and coagulase-positive. These 151 isolates were identified independently as $S$. aureus by the routine diagnostic laboratory. A further 323 isolates were $f e m B$-negative, DNAase-negative and coagulasenegative, and were identified as $S$. epidermidis by the routine diagnostic laboratory. Five isolates were positive in only one of the duplicate $\mathrm{femB}$ PCRs; one of these isolates was also DNAase-positive and coagulasepositive (and was identified as $S$. aureus by the routine diagnostic laboratory), while the other four isolates were DNAase-negative and coagulase-negative (and were identified as $S$. epidermidis by the routine diagnostic laboratory). These five discordant results may, therefore, represent one false-negative and four false-positive results, respectively, with the other PCR in each duplicate set giving the 'correct' result. A single final isolate (identified as $S$. epidermidis by the routine diagnostic laboratory) was positive with both femB PCRs, but was consistently DNAase-negative and coagulase-negative. This final 'false-positive' isolate was the only example (i.e., $0.3 \%$ ) of the 327 coagulasenegative isolates tested that was consistently femBpositive. Identical results were obtained in all cases by the PCR-immunoassay and by conventional electrophoretic analysis of PCR products on agarose gels. No non-specific PCR products were observed on agarose gels.

\section{Use of mecA in combination with femB to recognise $M R S A$}

The mecA gene is the primary structural gene required for methicillin resistance in staphylococci. It is essential for expression of methicillin resistance in 'true' MRSA, but can be found in a non-expressed state in methicillin-sensitive $S$. aureus and, either expressed or non-expressed, in many coagulase-negative staphylococci [10]. Of the $152 \mathrm{~S}$. aureus isolates examined, 40 were identified by the routine diagnostic laboratory as MRSA or '?MRSA'. Of these 40 isolates, only $24(60 \%)$ were confirmed as MRSA by PCR (i.e., $m e c A$-positive, $f e m B$-positive), 14 (35\%) lacked the $m e c A$ gene and would not be considered as MRSA by reference laboratory criteria [5], while two (5\%) lacked the $f e m B$ gene and were found on further repeated testing to be coagulase-negative staphylococci. In addition, of the remaining 440 isolates, two $(0.5 \%)$ were identified as MRSA by PCR and were positive in repeated coagulase tests, but were not originally reported as MRSA following initial tests by the routine microbiological laboratory. Identical results were obtained by the PCR-immunoassay and by conventional electrophoretic analysis of PCR products on agarose gels. No non-specific PCR products were observed on agarose gels.

\section{Use of the PCR-immunoassay to detect MRSA in routine patient screening swabs}

In total, 146 random sets of screening swabs (each set comprising pooled swabs from up to six body sites on an individual patient) were examined by the PCRimmunoassay in parallel with the conventional methodology used by the routine diagnostic microbiology laboratory. Of the 146 screens, 30 were reported as MRSA-positive by the routine laboratory. Of these, only $25(83 \%)$ were confirmed as MRSA-positive by the PCR-immunoassay. Repeated examination by conventional methodology failed to confirm the presence of MRSA in any of the five remaining enrichment broths from which 'MRSA' had been reported originally (Table 3 ). When the 116 enrichment broths reported as 'MRSA-negative' by the routine diagnostic microbiology laboratory were examined by the PCRimmunoassay, $10(9 \%)$ yielded a $m e c A$-positive, femBpositive result characteristic of the presence of MRSA. These 10 broths were also positive in repeated PCR tests.

\section{Detection of MRSA in screening swabs from previous known MRSA carriers}

In addition to the above examination of random sets of screening swabs, 100 swabs obtained from defined body sites on 13 patients shown previously by conventional methods to be colonised by MRSA were processed individually in enrichment broth and then examined by both methods. MRSA was detected by both methods on 18 swabs from eight patients. A further six swabs from four of these eight patients were

Table 3. Results of repeated conventional microbiological analysis of enrichment broths reported originally by the routine diagnostic laboratory as MRSA-positive but found to be MRSA-negative by the PCR-immunoassay

\begin{tabular}{ll}
\hline $\begin{array}{l}\text { Broth } \\
\text { no. }\end{array}$ & Microbiological content \\
\hline 1 & $\begin{array}{c}\text { Mixed staphylococci and enterococci; } S \text {. aureus isolate methicillin-sensitive and } \\
\text { confirmed as mec } A \text {-negative }\end{array}$ \\
2 & $\begin{array}{l}\text { Enterococci only } \\
\text { Methicillin-resistant } S \text {. aureus; isolate repeatedly confirmed as mecA-negative } \\
\text { (not MRSA by definition) }\end{array}$ \\
& $\begin{array}{l}\text { Methicillin-sensitive } S \text {. aureus; isolate confirmed as mec } A \text {-negative } \\
\text { Mixed staphylococci and enterococci; no } S \text {. aureus isolate obtained on repeated } \\
\text { culture }\end{array}$ \\
\end{tabular}


MRSA-positive only by PCR, and a single swab from one patient was positive only by conventional methodology. Subculture of the enrichment broth containing this final swab yielded a heavy mixed growth of coliforms, with very small numbers of staphylococci; however, these staphylococci were shown by PCR to be $m e c A$-positive, femB-positive following re-streaking to purity (i.e., a PCR false-negative result). A further 56 swabs from the same eight patients were MRSAnegative by both methods. The remaining five patients provided 19 swabs that were MRSA-negative by both methods.

\section{Discussion}

A number of previous studies have assessed the use of PCR-based strategies, with a range of DNA targets, for identification of MRSA [5, 10, 12, 14, 15]. Most of these studies have been concerned with the specific identification of bacterial strains already isolated in pure culture, although Vannuffel et al. [14] were able to detect small numbers of MRSA successfully in freshly collected spiked blood samples. In the present study, a PCR-based detection system was applied to specimens received in a routine laboratory as part of the normal diagnostic microbiology service. However, although detection of MRSA in routine clinical specimens may provide important information, this is, by itself, inadequate for control of infection purposes [16] and may become more unsatisfactory as lengths of hospital stay shorten and the numbers of clinical specimens decrease [17]. It is becoming increasingly apparent that screening for carriers, rather than simply identifying infected patients, will play a major role in the future control of MRSA outbreaks [3], and a study during a large and prolonged MRSA outbreak in Spain [18] has already shown that it is possible to reduce the number of infections with MRSA, and the associated mortality, by switching to a control strategy involving identification and treatment of carriers. Furthermore, as MRSA control strategies are re-evaluated in the light of changing circumstances, molecular approaches to diagnosis appear increasingly appealing, especially in efforts to reduce the 48-72-h delay seen with conventional methods [19]. For these reasons, the present study was concerned with evaluating the feasibility of detecting MRSA rapidly in patient screening specimens by extracting bacterial DNA from overnight enrichment broths and combining PCR amplification of the mecA and $f e m B$ genes with rapid detection of the specific PCR products in a novel immunoassay system.

The first stage in the development of the system involved the identification of a suitable rapid method for release of DNA from bacterial cells grown in enrichment cultures. Staphylococci are notoriously difficult to lyse efficiently by most rapid techniques, but the present study found that a commercially available reagent (Hybaid Recovery ${ }^{\mathrm{TM}}$ ), used in combination with a short period of microwave radiation, was superior to conventional techniques involving the use of lysostaphin or heating of cell suspensions (Table 2). Furthermore, the Hybaid reagent is claimed by the manufacturer to improve amplification yield and specificity, and to sequester cell lysis products that might inhibit DNA polymerases. Of the total of 480 purified staphylococcal isolates and 246 enrichment broths examined during this study, only one enrichment broth from a known MRSA-positive patient failed to yield the expected PCR product (this enrichment broth was shown subsequently to contain only very small numbers of staphylococci in combination with a heavy mixed growth of coliforms).

A second consideration involved the choice of PCR targets. The mecA gene is the primary structural requirement for methicillin resistance in staphylococci [8] and has been used as a PCR target in other studies $[5,10,12,14,15]$. It is important to note that DNAbased methods differ from phenotypic techniques in that they examine the genetic potential of an organism to exhibit resistance [20]. Problems with phenotypic tests, such as expression, tolerance or inoculum effects, which often make disk or MIC tests difficult to interpret, are no longer relevant, since it is the simple presence or absence of potential resistance genes that is detected. As evidenced by the results obtained in the present study, there are particular problems in the use of phenotypic methods to reliably distinguish MRSA from strains of $S$. aureus that express low-level methicillin resistance [5], and reference laboratories now consider that it is prudent to regard all $S$. aureus strains that are $m e c A$-positive as methicillin-resistant, regardless of their MIC [5]. However, the mecA gene is also found, either expressed or non-expressed, in a large proportion of coagulase-negative staphylococci [10]. Preliminary experiments with staphylococci identified by DNAase and coagulase tests demonstrated that the $f e m B$ gene, involved in controlling the expression of methicillin resistance and pentaglycine-side chain formation $[8,9]$, was an effective marker for recognising isolates of $S$. aureus; the $f e m B$ gene was detected by PCR in all 151 isolates of $S$. aureus examined, but in only one of 327 coagulase-negative staphylococci. Therefore, to distinguish MRSA with a high degree of probability from other mecA-positive staphylococci, it was decided to detect the $m e c A$ gene in a multiplex PCR with the $f e m B$ gene.

Assuming that the presence of the mecA gene is the 'gold-standard' by which a $S$. aureus isolate should be identified as an MRSA [5], it was clear from the comparative results with purified isolates that the routine diagnostic laboratory was experiencing difficulties in identifying these organisms correctly. Of the 40 isolates identified by the routine diagnostic laboratory as MRSA or '?MRSA', only $24(60 \%)$ 
carried the $m e c A$ gene, while two (5\%) lacked the fem $B$ gene and were found to be coagulase-negative on further testing. A further two $(0.5 \%)$ of 440 'coagulasenegative' isolates were identified as mecA-positive, fem $B$-positive by PCR, and were coagulase-positive on further testing. Similar discrepant results were obtained with routine patient screening specimens cultured overnight in enrichment broth and then examined directly by PCR. A greater number of positive results was obtained by PCR than by conventional methodology, and of the 480 staphylococcal isolates and 246 enrichment broths examined, only one enrichment broth $(0.4 \%)$ was PCR-negative and was subsequently demonstrated unequivocally to contain MRSA by culture, with the purified culture then yielding an MRSA-positive result by PCR. In the study by Kobayashi et al. [10], 4\% of the oxacillin-resistant $S$. aureus isolates examined did not produce a $\mathrm{fem} B$ PCR product. Therefore, although all $152 \mathrm{~S}$. aureus isolates in the present study were found to be $f e m B$-positive, the possibility of a rare aberrant $f e m B$-negative MRSA isolate should not be discounted completely.

It is difficult to be certain whether the 'additional' PCR results obtained were false-positives since, by definition, MRSA could not be identified by conventional methodology. An overall false-positive result would require both components of the multiplex PCR to simultaneously and spontaneously give a falsepositive result, a dual event that might be expected to occur at a very low frequency by chance alone. A theoretical possibility is that, in the case of the enrichment broths, a mixed bacterial population of $m e c A$-negative $S$. aureus and mecA-positive coagulasenegative staphylococci was being examined. Such a scenario would generate both PCR products, one from each constituent organism in the broth, even though no MRSA were present. However, such a situation is also unlikely (and could not be demonstrated by conventional methodology in any of the 'discrepant' enrichment broths examined in this study), since any $m e c A$-negative $S$. aureus cells present would be inhibited by the methicillin present in the broth and would probably not be present in sufficient numbers following the overnight enrichment period to generate the $f e m B$ product.

In conclusion, it is apparent that routine diagnostic laboratories encounter difficulties in identifying MRSA correctly. The multiplex PCR described in this paper offers a rapid alternative, with a high degree of specificity, for the examination of overnight enrichment broths. Results are available within $24 \mathrm{~h}$ of screening swabs arriving in the laboratory, compared with a minimum of $48-72 \mathrm{~h}$ by conventional techniques. The PCR-immunoassay adds significantly to the usefulness of the technique in routine diagnostic laboratories by allowing the detection of specific PCR products within 5 min of completing the PCR, without the additional time-consuming, technically demanding and rate-limiting step of agarose gel electrophoresis. Other authors have described alternative rapid strategies for detecting the mecA gene that involved an ELISA [21] or a solution phase DNA hybridisation capture assay [22], but these approaches did not combine detection of mecA with simultaneous recognition of $S$. aureus. The PCR-immunoassay described in the present paper offers a particularly user-friendly format and, overall, the PCR-immunoassay technique seemed to be more accurate than conventional methodology in detecting MRSA, with only one apparent false-negative result among the 480 isolates and 240 enrichment broths examined, compared with a possible 18 false-negative results obtained by conventional methodology. Occasional false-positive PCR results (see above) should be detectable and eliminated by performing all PCRs in duplicate, and would also be picked-up during repeat patient screens, but would in any event be an acceptable outcome on a rare basis in view of the potential consequences of failing to detect a patient colonised with MRSA at an early stage. Such early detection of MRSA will assist infection control teams in implementing preventative strategies and may assume even greater importance following the emergence in Japan of MRSA strains with reduced susceptibility to vancomycin [23].

We are indebted to Dr D. Swaine and Unipath Ltd for their interest and support of this work. We also thank Dr M. Crowe and $\mathrm{Mr} \mathrm{J}$ Gazzard for their assistance with some of the clinical and laboratory aspects of the study.

\section{References}

1. Voss A, Milatovic D, Wallrauch-Schwarz C, Rosdahl VT, Braveny I. Methicillin-resistant Staphylococcus aureus in Europe. Eur J Clin Microbiol Infect Dis 1994; 13: 50-55.

2. Thornsberry C. Epidemiology of staphylococcal infection - a USA perspective. $J$ Chemother 1994; 6 Suppl 2: 61-65.

3. Cookson B. Is it time to stop searching for MRSA? Screening is still important. $B M J 1997 ; 314: 664-665$.

4. Cox RA, Conquest C, Mallaghan C, Marples RR. A major outbreak of methicillin-resistant Staphylococcus aureus caused by a new phage-type (EMRSA-16). J Hosp Infect 1995; 29; $87-106$.

5. Bignardi GE, Woodford N, Chapman A, Johnson AP, Speller DCE. Detection of the mec-A gene and phenotypic detection of resistance in Staphylococcus aureus isolates with borderline or low-level methicillin resistance. J Antimicrob Chemother 1996; 37: $53-63$.

6. Curran R, Talbot DCS, Towner KJ. A rapid immunoassay method for the direct detection of PCR products: application to detection of TEM $\beta$-lactamase genes. J Med Microbiol 1996; 45: $76-78$.

7. Barrow GI, Feltham RKA (eds). Cowan and Steel's Manual for the identification of medical bacteria, 3rd edn. Cambridge Cambridge University Press. 1993.

8. Berger-Bächi B. Expression of resistance to methicillin. Trends Microbiol 1994; 2: 389-393.

9. Kopp U, Roos M, Wecke J, Labischinski H. Staphylococcal peptidoglycan interpeptide bridge biosynthesis: a novel antistaphylococcal target? Microb Drug Resist 1996; 2: 29-41.

10. Kobayashi N, Wu H, Kojima K et al. Detection of mecA, femA, and $f e m B$ genes in clinical strains of staphylococci using polymerase chain reaction. Epidemiol Infect 1994; 113: 259-266.

11. Hürlimann-Dalel RL, Ryffel C, Kayser FH, Berger-Bächi B Survey of the methicillin resistance-associated genes $m e c A$, 
mecRI-mecl, and femA-femB in clinical isolates of methicillinresistant Staphylococcus aureus. Antimicrob Agents Chemother 1992; 36: 2617-2621.

12. Geha DJ, Uhl JR, Gustaferro CA, Persing DH. Multiplex PCR for identification of methicillin-resistant staphylococci in the clinical laboratory. J Clin Microbiol 1994; 32: 1768-1772.

13. Sambrook J, Fritsch EF, Maniatis T. Agarose gel electrophoresis. In: Molecular cloning, a laboratory manual, 2nd edn. Cold Spring Harbor, NY, Cold Spring Harbor Laboratory. 1989: 6.3-6.19.

14. Vannuffel P, Gigi J, Ezzedine $\mathrm{H}$ et al. Specific detection of methicillin-resistant Staphylococcus aureus species by multiplex PCR. J Clin Microbiol 1995; 33: 2864-2867.

15. Barski P, Piechowicz L, Galínski J, Kur J. Rapid assay for detection of methicillin-resistant Staphylococcus aureus using multiplex PCR. Mol Cell Probes 1996; 10: 471-475.

16. Goldmann DA. Contemporary challenges for hospital epidemiology. Am J Med 1991; 19: 8S-15S.

17. Rahrnan A, Mackenzie D, Marples R, Cookson B. Identification of MRSA incidents in hospitals. $J$ Hosp Infect 1995; 30: $76-78$.
18. Coello R, Jiminez J, Garciá M et al. Prospective study of infection, colonization and carriage of methicillin-resistant Staphylococcus aureus in an outbreak affecting 990 patients. Eur J Clin Microbiol Infect Dis 1994; 13: 74-81.

19. Humphreys H, Duckworth G. Methicillin-resistant Staphylococcus aureus (MRSA) - a re-appraisal of control measures in the light of changing circumstances. J Hosp Infect 1997; 36: $167-170$.

20. Towner KJ. Detection of antibiotic resistance genes with DNA probes. J Antimicrob Chemother 1992; 30: 1-2.

21. Ubukata K, Nakagami S, Nitta A et al. Rapid detection of the $m e c A$ gene in methicillin-resistant staphylococci by enzymatic detection of polymerase chain reaction products. $J$ Clin Microbiol 1992; 30: 1728-1733.

22. Kolbert CP, Connolly JE, Lee MJ, Persing DH. Detection of the staphylococcal mecA gene by chemiluminescent DNA hybridization. J Clin Microbiol 1995; 33: 2179-2182.

23. Hiramatsu K, Hanaki $H$, Ino $T$, Yabuta $K$, Oguri $T$, Tenover FC. Methicillin-resistant Staphylococcus aureus clinical strain with reduced vancomycin susceptibility. J Antimicrob Chemother 1997 ; 40: $135-146$. 